\title{
Newsletter $N^{\circ}$ 7/2009
}

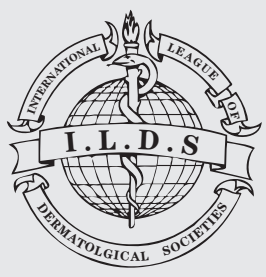

\section{Contents}

22nd World Congress of Dermatology

- Letter from Seoul

- ILDS Board Site Visit Report

23rd World Congress of Dermatology

- Letter from Bangalore

- Letter from Vienna

Update from the Administrative Officer

- ILDS Certificates of Appreciation 2007/2008

- ILDS Certificates of Appreciation 2009

- New Member Societies

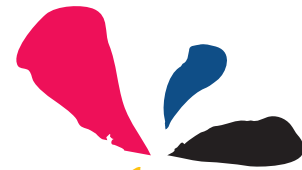

\section{2nd}

World Congress of Dermatology

Seoul 2011

\section{Site Visit for the 22nd World}

\section{Congress of Dermatology}

During May, one of the most beautiful months in Korea, 20 ILDS board members and their spouses visited Seoul from the 26th to the 29th for the 22nd WCD Site Visit.

During the visit, the preliminary draft of the scientific program was developed after inspecting the venue facilities and discussing the suitability of the locations for the planned events of the program.

The ILDS board meeting was held at the Grand InterContinental Hotel on Wednesday the 27th and Thursday the 28th. After the meeting on Wednesday morning, they moved to COEX, the main venue for the 22nd WCD, and examined the exhibition halls, conference rooms, and the related facilities. That same afternoon, the 2nd Program Committee Meeting and the IFD/Dermlink Committee Meeting were also held.

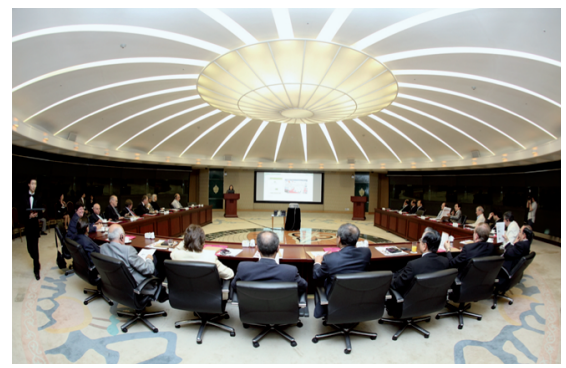

Venue presentation

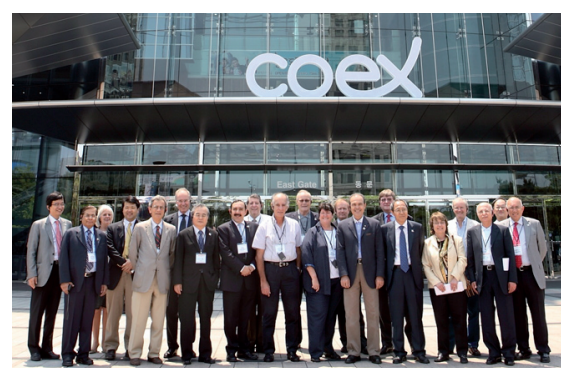

ILDS board in front of the 2011 congress center COEX

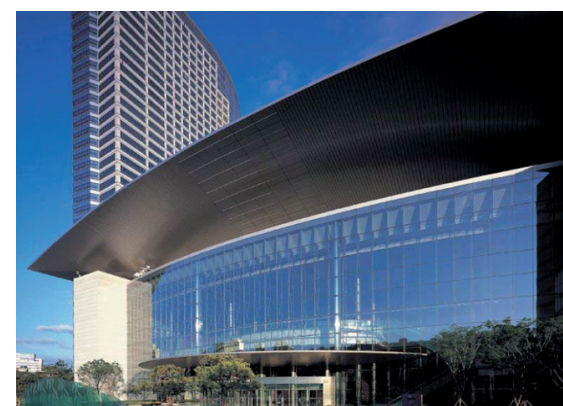

Front view of COEX, the main venue

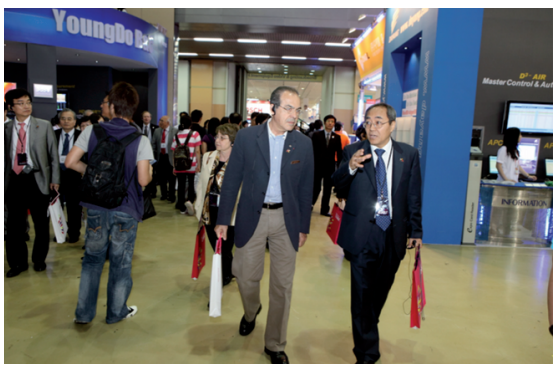

Booth (exhibition Hall) site visit

\section{Scientific Program}

Following the previous Program Committee Meeting in Berlin in February, the 2nd Program Committee Meeting was held during this site visit. The draft of the scientific program has finally been developed, and invitation letters to all the speakers and chair/co-chairpersons will be sent out at the beginning of July.

\section{The outline of the main scientific program is} as follows:

5 Special lectures

- Whole genome sequencing: impact on dermatology

- Innate immunity and the skin

- The role of inflammation in metabolic syndrome

- Adult skin cells: a source of stem cells

- Viral infections in the modern world

10 Advanced lectures

- Antimicrobial peptides: more than epidermal antibiotics

- Disorders of the epidermal barrier

- Skinomics: Molecular profiling as a diagnostic tool

- Melanoma: Do we need a new classification?

- Regeneration and repair

- Psoriasis: more than one disease?

- Acne and acneiform diseases

- STI and global migration

- Multiresistant bugs

- Stem cells in skin cancer 
In addition, 15 Hot Spot sessions, 158 Symposia and Workshops sessions, 21 Course sessions, and 14 Meeting of Minds sessions have been arranged. The rest of the sessions, including the Clinical Case sessions, Interactive Sessions, Ancillary Meetings, Satellite Symposia, Sponsored Symposia, and What's new sessions, will be arranged in detail in the future by the local organizing committee. In addition, the local organizing committee is planning a new scientific session called the Korean Dermatological Association (KDA) Seminar. This session may include 6 daily lectures ( 2 basic science and 4 clinical-oriented lectures) and will take place every morning during the Congress from 7 a.m. to 8 a.m. with light breakfast served to the attendees. Worldrenowned lecturers from various fields will be invited to speak at the KDA Seminar series.

Beginning with the 22nd World Congress of Dermatology, an E-poster system will be introduced to replace the traditional poster displays. All poster presentations will be received as either a PPT o PDF file online.

Compared to the 21st WCD in Buenos Aires, the scientific program will be strengthened through the addition of 21 sessions of Symposia and Work shops, 6 courses, and the ambitious KDA Seminar.

The 22nd WCD will be taking place around a similar time of the year as this board visit period, only 2 years later. The tour of the board members and the accompanying guests took place in a beau tiful climate. They applauded the perfect preparation of the local organizing committee, were satisfied with the venue facilities, and expressed confidence that the 22nd World Congress of Dermatology will be successful.

Hee Chul Eun, President

Soo-Chan Kim, Secretary Genera

22nd World Congress of Dermatology

\section{ILDS Board Site Visit Report May, 2009}

The International League of Dermatological Societies is the global organization promoting Skin Health. For over a century it has organized World Congresses of Dermatology, the most recent having taken place in Buenos Aires, Argentina in 2007, where over 12.000 dermatologists participated in updating their knowledge about our specialty.

The ILDS currently has 131 member societies from all over the world. Among most recent members are the Chinese Society for Dermatology, the Indian Association of Dermatology, Venereology and Leprology, the Mongolian Dermatological Society and the Dermatological Society of Vietnam illustrating the reality of global membership of the ILDS. The ILDS is recognised as the world dermatological body in relations with the World Health Organisation where it promotes projects ranging from International Disease Classification to children's medicines.

The ILDS' mission is to promote and improve skin health for all citizens of the world. This is not an easy or instant task. The ILDS has established a division called the International Foundation of Dermatology (IFD), which particularly focuses on dermatology in developing countries (current Chairman Roderick Hay). In 1987 a Regional Dermatology Training Centre (RDTC) was established in Moshi, Tanzania, where over 150 trainees from 15 different African countries have been educated during 2-year courses on how to diagnose and treat the most common skin and venereal diseases. These trainees have returned to their home countries and are working in their local settings. A residency training programme for African dermatologists is also run by the RDTC. Further, the ILDS has promoted epidemiological projects on skin health in Mali, Mexico and India and is planning further projects in Burkino Faso, Cambodia etc. The ILDS has many more ideas, but we have to be realistic and work within our economical possibilities.

Member societies of the ILDS send delegates to the General Assembly held during the world congresses and here they select:

\section{- The next site for the World Congress of \\ Dermatology}

- The members of the ILDS board

Recently, under the presidency of Robin Marks, elected 'regional board members' were introduced meaning that from the 5 regions of the world, two board members will be selected - securing a truly 'global dermatology structure' for the ILDS.

\section{The next and 22nd World Congress of} Dermatology (www.wcd2011.org)

Seoul in South Korea is hosting the WCD on May 24-29, 2011. So, it is now time to mark your calenders/mobile phones/PDAs. The motto of this Congress is: 'Connecting the World through Innovative Dermatology'.

The ILDS board was invited by our Korean hosts to visit Seoul on May 26-28, 2009, to see what they will be offering you as a participant in the WCD.

The meeting takes place in the COEX congress center. It is, in principle, a cubic structure, the centre of which contains meeting rooms - the largest being able to accommodate 7.000 persons, an enormous exhibition area - and altogether more than 150 rooms of which 15 will seat 500 persons or more. All traffic will move in spacious areas around the cubic structure which has 4 floors with escalators and elevators for ease of access for everyone. Thus, it is an all 'in-house' event with air-conditioning. The facilities for communication are excellent - with power point presentations, wireless communication, information on screens etc.. Korea will impress you with its communication abilities something which will be directly of help where, as an example, tele-dermatology is now offered to our colleagues working in Medicins Sans Frontieres, who can connect to the IFD for questions on diagnostic problems from all over the world.

Go to www.coex.co.kr where you can find detailed information.

\section{Korea and Seou}

Seoul is a huge city with 12 million inhabitants and if you include the surrounding cities, approx. 20 million inhabitants. It is modern with many tall buildings. It is divided by the Han river, crossed by 26 bridges with bustling traffic. The transportation system is best via subway, and the best option is to reserve your hotel either in or within walking distance to the congress centre.

As modern and efficient as the congress venue is - you can just cross the street to the Bongusunsai Temple - a Buddhist Monastery used daily by monks and visitors. This is a peaceful place to meet Asian culture - amidst its modern surroundings.

Although Seoul is central to Korea, it is not the soul of Korea. Consider a trip outside Seoul to see beautiful landscapes and places. Visit the website www.visitkorea.or.kr for that purpose. Our Korean colleagues are establishing lots of options for you.

Seoul is safe. You do not need to worry about hazards. The COEX center has its own police station and the streets are safe at night. As is the subway system.

\section{Going to Seoul}

Seoul is, as a major city, well connected to the world. For us coming from the Nordic countries, Finnair has a very smooth and very quick connection - likely the quickest from Europe. It takes only $8 \frac{1}{2}$ hours from Helsinki directly to Seoul. Incheon Airport is huge and very modern and connections to central Seoul takes about 1 hour as the airport is $60 \mathrm{kms}$ outside the city (www.airport.kr) - you will find all details there.

\section{Why attend the next world congress?}

I have four arguments:

- To receive an update on your specialty with experts from all over the world

- To support global dermatology by being an active member of ILDS

- To meet friends - and make new friends

- To visit Korea and Asia - an option which is not an everyday opportunity

What to see in Seoul - or 'the soul of Seoul'? Below are a number of suggestions for things to do besides the congress:

- You should visit the Bongusunsai Temple. It's easy, just cross the street from COEX. And - it is a temple in daily use

- You should go to the National Museum of Korea

- You should visit the Leeum Museum, not only for its exhibits of beautiful ancient Korean pottery, but also for its innovative achitecture

- And for shoppers i.e. persons where the transcription factor for the shopping gene is very active - COEX has a basement with hundreds of shops and cafes - and the Hyundai Department store carries everything (www.ehyundai.com). It is within 5 minutes walk from the COEX.

\section{List of websites:}

- www.ilds.org

- www.wcd2011.org

- www.coex.co.kr

- www.visitkorea orkr

- www.airport.kr

- www.museum.go.kr

So, go a day or a week before the congress, choose a hotel as close as possible to the COEX area, visit places listed above - and then enjoy participating in a congress very well prepared by our hosts and enjoy Korean hospitality.

\section{June 2009}

Kristian Thestrup-Pedersen, MD, PhD 


\section{3rd World Congress of Dermatology}

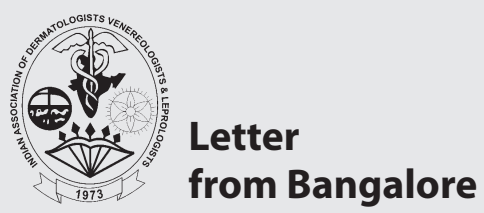

Indian Association of Dermatologists, Venereologists and Leprologists (IADVL) is a robust and dynamic organization of more than 6000 members. It is closely associated with several sister associations such as Association of Cutaneous Surgeons of India (ACSI), Contact and Occupational Dermatology Forum of India (CODFI), Cosmetic Dermatology Society of India (CSI), Indian Society of Paediatric Dermatology (ISPD), Trichology Society etc.. Ove the years this organisation has grown from strength to strength and is one of the largest bodies of its kind. Several experienced and qualified Dermatologists have already made their mark at the International level. They have been regular invitees to various International conferences and symposia. Several of them are the authors of well appreciated books and are on the editorial boards of several international journals. Besides IADVL is itself publishing the Indian Journal of Dermatology, Venereology and Leprology (IJDVL), a journal which has already made long strides in the global Dermatology scenario. We also have Indian Journal of Dermatology (IJD), a Paediatric Dermatology journal brought out by Indian Society of Paediatric Dermatology (ISPD), Journal of Cutaneous and Aesthetic Surgery brought out by Association of Cutaneous Surgeons of India (ACSI), Indian Journal of Leprosy brought out by Hind Kusht Nivaran Sangh and the Journal of IASTD and AIDS brought out by the Indian Association of Sexually Transmitted Diseases and AIDS (IASTD), International journal of trichology. IADVL is also in the fore front of establishing standards of care in dermatology practice and to enhance evidence based practice, several therapeutic guidelines and dermato-surgical guidelines have been established.

IADVL has been organizing DERMACON an annual National conference which is being attended by around $4500-5000$ dermatologists. This conference is currently attracting delegates not only from the neighbouring SAARC nations, but also from other nations like UAE, Bangkok, Malaysia, Singapore, Mauritius, Sub Saharan African countries and few European Nations as well. Several speakers of International reputation have been regularly attending and delivering lectures and interacting with our delegates.
We have hosted several international conferences in the past. These include ICD during 1994, IMCAAS 2008 at Agra, and have been pioneers in organizing several innovative conferences like PHOTOCON 2004, TRICHOCON 2005, COSMECON 2006, FOTOCON 2009 etc. Other international conferences held include World Congress of Teledermatology 2008, Cosmetic dermatology meetings in association with ESCAD, Dermatopathology meetings in association with international Universities etc. These conferences on focused subjects were big draws with lot of enthusiasm shown by dermatologists.

India is a developing nation with vibrant economy, unaffected by the recent global economic recession and is the only nation showing steady growth in GDP. Its several metropolises like New Delhi, Mumbai, Chennai, Kolkata, Bangalore and Hyderabad are potential venues for the World congress. The Indian culture and cuisine and several places of historical interest including the Taj at Agra beckons the world dermatology community.

With the prevailing excellent academic atmosphere mentioned above in India, the enthusiasm and zeal of the members, and experience of having organized conferences of International repute previously, and the promise that we shall leave no stone unturned to conduct a conference of International standards, we the members of IADVL, are genuinely interested to host the ensuing World Congress of Dermatology 2015. India welcomes the world dermatology community to come and savour our academic feast and our rich cultural heritage.

\section{Dr. S. Sacchidanand}

M.B.B.S., M.D., D.V.D., D.H.A

Convenor, WCD Bidding Committee

Registrar Evaluation, Rajiv Gandhi University of Health Sciences, Karnataka, Bangalore

Former Professor \& H.O.D., Department of Dermatology, S.T.D., \& Leprosy, Bangalore Medical College and Research Institute, Bangalore, India

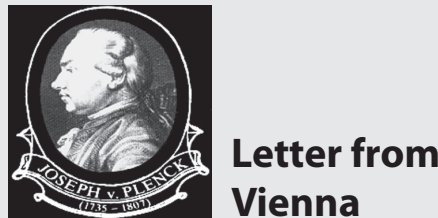

The Austrian Society of Dermatology and Venerology (ASDV) has decided to consider to bid for the World Congress of Dermatology in 2015. Vienna is located in the heart of Europe. It has strong historical and, thus, cultural links to all its neighbour states and has been greatly influenced by them. This is also true for dermatology in that two of our country's giants, e.e. Hebra and Kaposi, came from

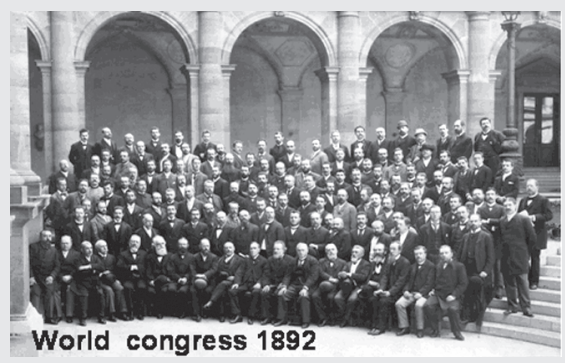

Moravia and Hungary, respectively. The Austrian dermatologists were the first to hold a scientific meeting in Central Europe in 1890. Two years later Moriz Kaposi was the president of the second World Congress of Dermatology in Vienna. The city had a marvelous convention center at that time - the famous Rotunde - an impressive round exhibition center built for the World exhibition in 1888 .

It may not be mere incidence that the modern convention center, which may host up to 20.000 participants is located in the same downtown area, surrounded by the Prater with its famous 'Riesenrad'. The Vienna Messe-Center is equipped with advanced technologies serving convenient lecture halls and large space capacities for exhibitions. The Messe Center is within walking distance from the center of Vienna, which is (still) one of the safest urban areas worldwide. The evening you may easily reach the Vienna opera house or the 'Burgtheater' for cultural highlights or the 'Ringstrasse' just for a walk. For those who prefer the beauty of nature, arrangements will be made to visit the 'Wienerwald' or to enjoy the excellent local wines and food in the 'Heurigen'. Vienna has excellent public transportation and is well accessible by air, train, and even by boat via the river Danube. Vienna thus perfectly combines professional, cultural and leisure activities in one spot.

Johannes Bauer, MD - Secretary Beatrix Volc-Platzer, MD - President

On behalf of the Board of the Austrian Society of Dermatology and Venerology 


\section{Update from the Administrative Officer}

\section{ILDS Certificates of Appreciation 2007/2008}

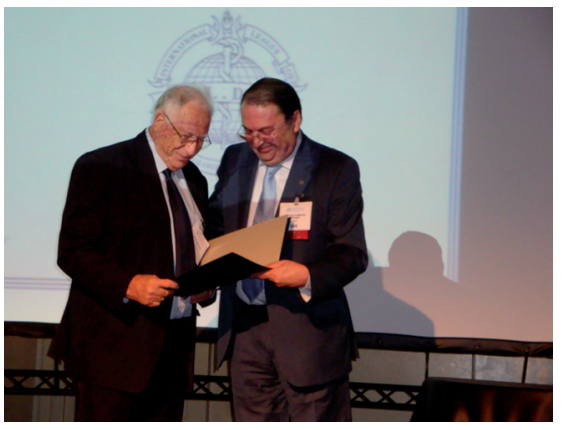

Dr. Aryeh Metzker (left) receiving his ILDS Certificate of Appreciation (2008) from ILDS Board Member Professor Camacho-Martinez in May this year at the 12th World Congress on Cancers of the Skin in Tel Aviv.

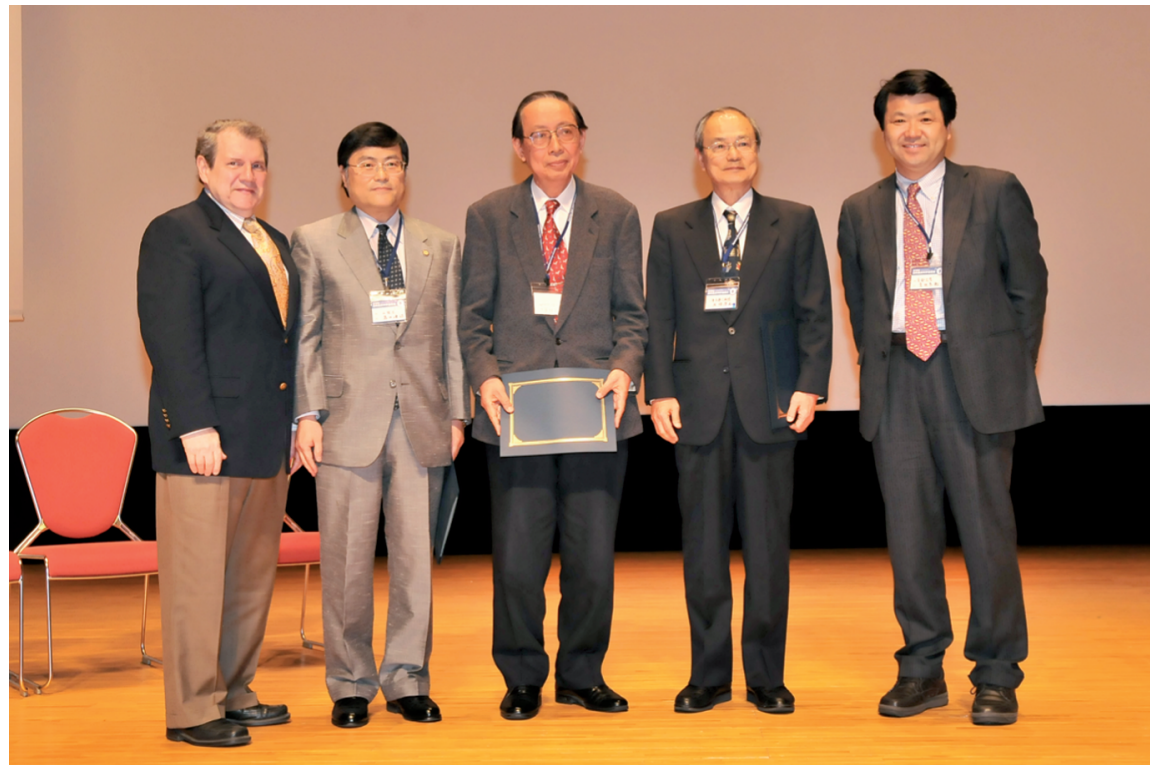

From left to right Professor Stephen Katz, former President of the ILDS, Professor Shinji Shimada, Professor Sadao Imamura, Professor Yasumasa Ishibashi and ILDS Board Member Professor Yoshiki Miyachi. Professors Shimada, Imamura and Ishibashi were presented with their ILDS Certificates of Appreciation at the Annual JDA Meeting in Fukuoka, Japan in April, this year.

\section{ILDS Certificates of Appreciation 2009}

The ILDS Board met in Seoul in May this year and awarded the following nominees the ILDS Certificate of Appreciation 2009. Congratulations are extended to all by the Board.

\begin{tabular}{|l|l|}
\hline Name of Nominee & Proposed By \\
\hline Ashok Kumar Bajaj & Indian Association of Dermatology, Venereology and Leprosy \\
\hline Jean L. Bolognia & Women's Dermatologic Society \\
\hline Hongduo Chen & Chinese Society of Dermatology \\
\hline Yasuo Kitajima & Japanese Society for Investigative Dermatology \\
\hline Preya Kullavanijaya & Dermatological Society of Thailand \\
\hline Walter G. Larsen & American Academy of Dermatology \\
\hline Riad Mashal & Palestinian Society of Dermatology \& Venereology \\
\hline Albert-Adrien Ramelet & ILDS Board \\
\hline Alain Taieb & European Society of Pediatric Dermatology \\
\hline Fenella Wojnarowska & British Association of Dermatologists \\
\hline
\end{tabular}

\section{New Member Societies}

Two new Societies were also accepted into the League at this time and will become National Society members as of 1st January, 2010. We are delighted to welcome:

- Italian Society of Allergological, Occupational and Environmental Dermatology (SIDAPA)

- Dermatological Society of Vietnam

\section{E. Arnold, London}

